\title{
Design Estratégico para e com deficientes visuais: uma abordagem participativa usando ferramentas adaptadas ao usuário
}

Strategic Design for and with the visually impaired: a participatory approach using tools adapted to the user

\author{
MACCAGNAN, Ana Maria C.; Bacharel; Unisinos \\ anamacc18@gmail.com \\ MEYER, Guilherme Englert Corrêa; Doutor; Unisinos \\ gemeyer@unisinos.com.br
}

\begin{abstract}
Resumo
A demanda de atuação do profissional de design em desafios cada vez mais sistêmicos e complexos vem refletindo no surgimento de novos papéis dentro do campo do design. Necessitase um profissional que amplie sua atuação para os campos da responsabilidade social ao engajarse ativamente em processos de criação participativa. Partindo do objetivo de projetar um sistema de informações urbanas multissensoriais que favoreça a mobilidade acessível e a autonomia de deficientes visuais num contexto situado, foram investigadas formas de engajar o usuário e profissionais da área através do uso de ferramentas provenientes da metodologia participativa e adaptadas aos participantes. Buscou-se na pesquisa a compreensão do âmbito no Design Estratégico quando trabalhado com um tema de demanda social. Dessa forma, explora-se os efeitos gerais do desenvolvimento de um projeto colaborativo, gerando empatia e imersão em contexto e entendendo outras qualidades do protótipo para além de sua visualidade.
\end{abstract}

Palavras Chave: Design Estratégico; Design Participativo; Deficiência visual.

\begin{abstract}
The performance demand of a professional designer in the increasingly systemic and complex challenges has been reflected in the emergence of new roles in the field of design. A professional that broadens its performance and social responsibility by engaging actively in co creation processes is needed. Starting from the project objective of designing a multi-sensory urban information system that promotes accessible mobility and autonomy of the visually impaired in a situated context, some ways to engage the user and professionals were investigated through the use of tools from participatory methodology and adapted to the participating public. It was sought to understand the scope of the Strategic Design when working with a theme of social demand. In this way, explores the overall effects of developing a collaborative project, generating empathy and immersion in context and understanding other qualities of prototypes beyond its visuality.
\end{abstract}

Keywords: Strategic Design; Participatory Design; Visually Impaired. 


\section{Introdução}

Novos papéis dentro do campo do design têm sido percebidos, onde o profissional preocupa-se primeiramente em melhorar a qualidade de vida dos usuários, demonstrando maior preocupação e responsabilidade social. Um profissional que não reduz sua atividade a uma mera operação técnica, ou que pense em criar novas disciplinas que cubram as questões sociais, mas que esteja ciente que está sendo demandada uma nova cultura e maneira de olhar o mundo (Manzini, 2017). Essa atualização não admite que o design restrinja-se a criar produtos, em suas diferentes formas, para o mercado de consumo, mas que torne-se uma profissão que demonstre uma responsabilidade social, aceitando desafios que têm como objetivo contribuir para o bem estar e mudanças de conceitos enraizados, promovendo também a inclusão social e o empoderamento de usuários em situações delicadas.

Neste sentido, é trazido neste artigo, como um contexto complexo, o grupo social das pessoas com deficiência visuais. Uma deficiência que no Brasil afeta cerca de $18,6 \%$ da população, de acordo com a cartilha do Censo (2010), sendo esta uma faixa da sociedade que frequentemente apresenta-se desprovida de oportunidades, encontrando-se em situações de invisibilidade perante a sociedade dita como "normal", como consequência do pouco convívio em espaços comuns.

O design, portanto, quando voltado para um papel social, consiste em desenvolver soluções que atendam às necessidades reais do seu usuário, em especial de uma parte da sociedade menos favorecida social, cultural e economicamente. Atuando em áreas onde, geralmente, não há apelo e nem interesse da indústria. Para que isso ocorra, é essencial que os métodos de Design Estratégico sejam adaptados ao público e que exista um elo de diálogo (Manzini, 2004).

De forma a receber contribuições do usuário para quem se está projetando, o Design Estratégico e sua habilidade de resolver problemas complexos através de uma capacidade de pensar além do problema e do tempo presente, mostrou-se importante aliado ao Design Participativo. Uma metodologia que propõe um trabalho realizado o mais próximo possível do usuário final, decifrando suas dificuldades, desejos e percepções. Ela auxilia a entender mais problemas tangíveis e intangíveis que acometem o deficiente visual, ao propor utilizar ferramentas de geração de empatia e de imersão em contexto, as quais têm como qualidade a sensibilização do projetista e a construção de um vínculo de confiança (Sampaio, Camino e Roazzi, 2009).

No presente artigo serão apresentados os resultados da pesquisa que teve como objetivo levantar possibilidades do design enquanto atividade capaz de entender quais as maiores dependências e desafios de um deficiente visual. Dessa forma, contribuindo na eliminação de barreiras físicas e sociais do público ao potencializar a experiência de autonomia com foco na mobilidade urbana acessível.

A pesquisa teve como desafio o próprio contexto definido, a escolha do público deficiente visual e a abordagem metodológica participativa. Fizeram-se necessárias a utilização de ferramentas participativas, sendo algumas, adaptadas para o uso do público durante o processo, entendendo que esta adaptação contribuiria para que os insights fossem muito mais ricos, e que a relação com o público fosse de maior confiança. Dessa forma, a pesquisa valorizou propósitos de integração ao projetar para e com as pessoas, prestando atenção na pessoa antes do usuário e desenvolvendo os princípios de inclusão ao prever segurança, usabilidade e dignidade (Franzato 2017). Para a realização da pesquisa foram estudados de forma resumida a esfera da deficiência 
visual e âmbitos significativos da área do design, para então seguir para as etapas de projeto.

\section{Revisão de Literatura}

\subsection{Design Estratégico e Wicked Problems}

Design, uma atividade que lida com a estreita relação de compreensão de problemas complexos tidos como wicked problems. Tal compreensão requer um processo de construção de significados e exploração que proporcionem variadas possibilidades de respostas ao problema. 0 Design Estratégico, por sua vez, representa um momento de projeto com características específicas e estratégicas, que caracterizam uma etapa de problem finding (Franzato, 2010 e Scaletsky, 2016).

O Design Estratégico é composto pela união da perspectiva da criação de sentidos e significados, da capacidade de pensar e realizar coisas que envolvem senso estratégico, e de uma atividade projetual criada em conjunto, através do diálogo entre disciplinas e entre atores, aproximando a organização, o usuário e o profissional de design (Meroni, 2008; Manzini, 2017).

A característica do diálogo proposto pelo designer estratégico com os atores, possibilita que se relacione com diferentes áreas, distintas à profissão, promovendo abertura para que novos participantes de projeto de possíveis áreas externas exponham seus conhecimentos igualmente. Assim, enriquecendo a criação de um projeto, quando utilizada a visão completa do todo e das partes através destes autores externos e trabalhando como moderador e estrategista dos processos (Scaletsky, 2016).

O Design Estratégico possibilita um resultado onde são desenvolvidos produtos, serviços, comunicação e experiência. Tendo como diferencial de destaque a capacidade de concepção através de um sistema-produto, o conjunto da integração destes fatores de uma organização, e que devem ser concebidos ao mesmo tempo (Meroni, 2008). Para melhor compreender a abrangência do problema, também propõe uma outra etapa ao processo de projeto, o metaprojeto. Esta destina-se a interpretar a realidade e contexto no qual o projeto será inserido, utilizando de ferramentas do design e estratégias "facilitadoras do pensamento" (Scaletsky, 2016).

Muitas vezes, porém, os problemas demandados acabam por serem considerados de difícil solução, também conhecidos como wicked problems. Um termo criado em 1973 que define problemas perversos, extremamente complexos, possivelmente de escopo indeterminado (Rittel e Melvin, 1973). Anos atrás, a ideia de planejar e definir um problema era considerada sinônimo de profissionalismo e eficiência, onde tarefas específicas realizadas com eficiência significavam economia de recursos. Já nos tempos atuais, definir um problema torna-se uma tarefa mais complexa, pois vem acompanhado de uma série de perguntas que auxiliam a melhor definir fronteiras de todo um sistema (Rittel e Melvin, 1973).

"Eles (problemas de política social) são problemas "arredios", e a ciência se desenvolveu para lidar com problemas "domesticados". Problemas de política pública não podem ser descritos de maneira definitiva. [...] políticas públicas que buscam lidar com problemas sociais não podem ser significativamente corretas ou falsas" (Rittel e Melvin, 1973, p.155). 
Problemas sociais podem ser considerados, portanto, wicked problems. Visto sua natureza complexa. Neles, é difícil definir pontos finais e um objetivo único e certo, visto que apresentam geralmente mais de uma possível resposta ao problema, assim como possíveis ramificações confusas do sistema. Quando trabalhado o tema de demanda social, a inclusão de deficientes visuais, foi possível identificar certas prioridades dentro de uma problema central, assim como foi percebida a importância de buscar o usuário como auxílio para as definições de projeto.

\subsection{Metodologia das Ferramentas Participativas}

Quando o design trabalha com foco na criação de artefatos inclusivos, os autores Falcato e Bispo (2006) salientam que organizações que projetam sem necessariamente incluir o público no processo, ou seja, sem a fonte core da informação, correm o risco de ter como resultado projetos que não necessariamente são aceitos pelo público-alvo. Devendo por isso, optar por uma pesquisa qualitativa, participativa e de observação, onde as experiências do usuário e público vão enriquecer o projeto.

O Design Participativo é uma prática que aplica o princípio de envolver os usuários no processo, não apenas os deixando como objetos passivos de estudo (Sanders, 1999). Nela, profissionais com especialidade em métodos de design trabalham conjuntamente com pessoas que possuem menos ou nenhuma vivência com eles (pessoas de diferentes contextos, experiências, profissões, origens, interesses e papéis dentro do projeto), envolvendo-se conjuntamente em processos de co-design. Desta forma, reforçando a ideia de que todos os atores têm pontos importantes para agregar ao projeto, mesmo que de diferentes contextos. Especialmente quando há utilização apropriada de ferramentas que permitam que estas pessoas se expressem de forma crítica e equivalentemente rica (Sanders, Brandt \& Binder, 2010).

Dentre os elementos que fazem parte do Design Participativo, pode-se salientar alguns itens como o desenvolvimento de um sentimento de empatia e a necessidade de imersão no contexto desenhado. Ambos são gerados através de elementos contextuais capazes de influenciar o projetista, como: lugar, participantes e o contexto em que está ocorrendo a situação. Elementos estes que devem ser, preferencialmente, diferentes do que é usualmente vivido pelo designer, apresentando consideráveis diferenças culturais e sociais que tiram-o do lugar comum (Del Gaudio, Oliveira \& Franzato, 2014).

A empatia é a habilidade de entender e se sensibilizar pelos sentimentos de outra pessoa, sem que se tenha vivido a mesma experiência. Uma habilidade que busca estabelecer vínculos cognitivo-afetivos entre pessoas, onde uma envolve-se emocionalmente com a vida privada da outra (Sampaio, Camino \& Roazzi, 2009). No contexto do design, a empatia permite introduzir-se emocionalmente no entendimento das necessidades do público (muitas vezes não expressas verbalmente por ele), para inspirar-se e assim transformar o próprio trabalho (Battarbee, Suri \& Howard, 2014).

Por sua vez, o envolvimento com um contexto desconhecido ou pouco explorado pelo designer mostra-se também um elemento importante. Aqui ressalta-se, que quando trabalhado com co-design nestas situações, o papel do designer deve sofrer sutis mudanças. O profissional passa a trabalhar em conjunto com os usuários, atuando como facilitador dos processos e das novas experiências e conhecimentos expressos pelos usuários (Meroni, 2008).

A imersão completa ocorre quando há uma total compreensão do contexto e uma criação 
de um sentimento de empatia pela situação, pelo usuário e o papel social a ser desempenhado. A dedicação em nível temporal da pesquisa deve ser também valorizada, pois contribui na construção da confiança e familiaridade do designer com os usuários e fatores apontados (Sanders, 2002; Del Gaudio, Oliveira e Franzato, 2014). O resultado de uma pesquisa que dedica-se a dar voz à seu público, apresenta-se com maior capacidade de impacto, beneficiando um maior número de pessoas, trazendo maior valor ao negócio e efeitos positivos.

\subsection{Contexto do Deficiente Visual e Relação com o Espaço}

"Na cultura ocidental, a visão tem sido historicamente considerada o mais nobre dos sentidos e o próprio pensamento é igualado à visão." (Pallasmaa, 2005, p. 15). A crença popular aponta que a visão é o sentido que mais predomina na experiência humana, sendo muitas vezes apontada como o sentido dominante, o que se deve, especialmente, por vivermos em um mundo em que prevalecem os estímulos visuais.

O sentido visual pode, de fato, facilitar o relacionamento do homem com a sociedade, mesmo não sendo essa uma capacidade inata ou um processo consciente. Há porém, outras maneiras de responder ao mundo e receber suas informações, no caso do deficiente visual, que se apresenta incapacitado de utilizar de estímulos visuais, acaba por fortalecer outras fontes de estímulos sensoriais, como a audição (sentido de ecolocalização e localização de sons), tato (sistema háptico), olfato e paladar (MEC, 2000).

Ainda que fortalecendo outros sentidos, os deficientes visuais podem apresentar dificuldades em realizar suas atividades diárias e um aumento da dependência sobre outras pessoas, o que influi diretamente na diminuição de seu senso de autonomia. Também, apresentam uma relação bem delicada com o espaço, sendo necessário se munir de diversos sistemas-guias nos momentos de locomoção e localização. Orientar-se espacialmente, torna-se para o cego um conjunto de noções do espaço físico: identificação de lugares, pontos referenciais e rotas (Dischinger, 2000).

Quando se fala do contexto do público, logo se fala de acessibilidade. O termo, muitas vezes, é associado à eliminação de barreiras físicas que impossibilitam a mobilidade, porém, a acessibilidade na verdade pode ser comprometida por outras barreiras que não exclusivamente as físicas, como: Barreiras Ambientais Físicas (arquitetônicas ou naturais); Socio-culturais e Intrínsecas (relacionamento entre pessoas e consigo mesmo); Externas de Informação e Comunicação (Bins Ely, 2004). A acessibilidade espacial do deficiente visual trata do acesso aos mais variados lugares e do uso de equipamentos de maneira autônoma, e é principalmente através da informação e da mobilidade - poder ir e vir - que o indivíduo consegue sentir-se parte e fazer parte da sociedade, participando dos lugares e das atividades, e estabelecendo contato com pessoas, ou seja, exercendo seu direito de cidadania.

Para o EDF (2002), a construção de fatores que levam à inclusão poderiam ser realizados consultando o público com deficiência e prestando atenção em suas necessidades e na nãocolocação de mais barreiras que acabam por excluí-los. Além disso, construir junto com o usuário evita que sejam cometidas generalizações, que consolidarão auxílios não práticos ou úteis, que podem reforçar ainda mais estereótipos errôneos. Na seguinte pesquisa, portanto, foi feito um trabalho junto ao público, tendo como participantes do processo deficientes visuais e profissionais da área, que trabalharam em conjunto a compreensão de dificuldades e barreiras através da 
criação, projetação e validação usando ferramentas de design participativas adaptadas. No processo de design, considerou-se os conflitos que se manifestavam ao longo do projeto.

\section{Método}

A pesquisa foi construída relacionando a metodologia do Design Estratégico à metodologia Participativa, e unindo ferramentas retiradas do Toolkit da IDEO 2009, o qual, propõe uma abordagem de Human-Centered Design. Algumas das ferramentas utilizadas tiveram que ser adaptadas para as práticas no contexto do usuário deficiente visual.

Assim como o Design Estratégico, o processo do Design Centrado no Ser Humano também não é tido como um processo linear. Procurou-se, portanto, articular em função dos próprios movimentos do projeto, aspectos do processo de Design Estratégico (tal como o metaprojeto) aos estágios de método propostas pelo Toolkit mencionado. Chegando a seguinte pré-estrutura projetual: (1)Ouvir ou fase de Inspiração, na qual ocorre o conhecimento das pessoas, suas necessidades, expectativas e aspirações, através das entrevistas e observações, nesta etapa foi desenvolvido o metaprojeto; (2)Criação ou fase de Ideação: síntese do conhecimento adquirido, identificação de oportunidades e geração de ideias em conjunto com o público. Fase onde se utiliza as ferramentas do design voltadas à interação com o usuário, desenvolvimento dos concepts e início do projeto final; (3)Entrega ou fase de Implementação: tirar as soluções do papel com o auxílio das validações dos usuários através da prototipação. Uma etapa prévia a estas três foi planejada para a definição do Briefing.

A pesquisa foi realizada em conjunto com o público deficiente visual (seis pessoas cegas e de três com baixa visão, entre 35-60 anos, sendo funcionários da instituição ou trabalhadores de outras áreas mas que mantêm vínculo com a instituição FADERS) e profissionais da área (psicólogas, terapeutas ocupacionais e psicopedagogas). Para tal proposta, foi escolhida como organização auxiliar da pesquisa a FADERS (Fundação de Articulação e Desenvolvimento de Políticas Públicas para Pessoas com Deficiência e com Altas Habilidades no Rio Grande do Sul) uma instituição que promove e apoia a pesquisa sobre o público deficiente. Os demais participantes da pesquisa, público deficiente visual e outros profissionais da saúde, vieram através do contato da FADERS e instituições relacionadas.

Entre as ferramentas utilizadas, Sanders (2002) ressalta a importância da técnica do diálogo no acesso a empatia com o usuário, assim como a importância de atividades que proponham a criação pelo usuário. Dessa forma, para a coleta de informações e geração de insights e ideias, foi utilizado preferencialmente o diálogo em entrevistas ao telefone ou presenciais em seus espaços de trabalho e residências; momentos de co-criação com grupos focais ou um usuário por vez; e validações presenciais com usuários e testes com protótipos.

\section{Resultados}

Nesta sessão de resultados, são apresentadas as etapas de desenvolvimento do projeto, não com o objetivo de apresentar seu resultado final, mas focando nas ferramentas utilizadas para 
a criação com a participação do usuário. A presente pesquisa apontou para a necessidade do desenvolvimento de um projeto que teve como foco a criação de um sistema de informações urbanas multissensoriais voltado ao público deficiente visual, favorecendo sua mobilidade urbana acessível e promovendo experiências positivas, autonomia e, por consequência, a inclusão do usuário em meio à sociedade. Para a sua realização, foi utilizada a metodologia do Design Estratégico junto a momentos participativos, que se muniram de ferramentas de design, precisando que algumas delas, fossem adaptadas ao contexto do usuário para melhor comunicar seu propósito, dialogar com o público e gerar empatia.

\subsection{Etapa de Briefing e Sensibilização:}

O projeto teve início na etapa de definição de Briefing, sendo dividido em: pesquisas field, realizando entrevistas com um deficiente visual em seu ambiente de trabalho e com uma profissional da FADERS; e pesquisas desk, analisando projetos e documentários.

Este primeiro momento foi de sensibilização quanto ao público e ao profissional que lida com a deficiência, e teve como objetivo começar a colher e reunir insights e compreender suas necessidades. Foram realizadas conversas sobre uma visão geral do âmbito "problemas e cotidiano de um deficiente visual" por meio da escuta genuína e da conversa aberta, utilizando o diálogo como ferramenta. Foi possível, principalmente através do ponto de vista de um deficiente visual, se sensibilizar mais sobre o tema e, da mesma forma abrangente, conhecer mais sobre o assunto. Característica marcante já no início da entrevista, foi que o entrevistado se descreveu como uma pessoa extremamente confiante, mesmo com suas dificuldades, o que incentivou uma percepção da capacidade de superação e adaptação deste público. Também foi possível já perceber uma necessidade buscar recursos que auxiliassem no dinamismo das conversas, visto que não haveriam recursos visuais para auxiliar no fluxo da entrevista. O resultado da etapa foi a compreensão da necessidade de busca por autonomia nos diferentes níveis de complexidade presentes na vida cotidiana do público.

\subsection{Etapa de Ouvir e Inspiração:}

A etapa seguinte, etapa Ouvir ou fase de Inspiração, teve como foco pesquisas contextuais e não contextuais (dentro do Metaprojeto) que serviram para conhecer mais quais eram as necessidades dos usuários tecnicamente e identificar oportunidades dentro do que se entendia como a autonomia deste grupo. Foram realizadas entrevistas presenciais em grupo focal com profissionais, também pesquisas de cases de projetos relacionados. Este momento foi importante para fortalecer os vínculos de confiança com as profissionais, que foram as responsáveis pelos agendamentos de entrevistas e atividades seguintes com os deficientes visuais.

O grupo focal foi realizado com quatro funcionárias da FADERS e CADEP (psicólogas e terapeutas ocupacionais) e foram discutidas questões relacionadas a autonomia do usuário e dificuldades mais técnicas da deficiência. Como suporte para a discussão, foram utilizados dois mapas da empatia de diferentes usuários: cego congênito x cego adquirido. 0 mapa da empatia é uma ferramenta que auxilia a sintetizar observações, identificando o que o usuário pesquisado diz, pensa, sente e faz (Ideo, 2009). A atividade estimulou as profissionais a conversarem mais sobre as experiências vividas em suas carreiras com o usuário, sendo ele paciente, aluno ou colega; e experiências que foram contadas pelos próprios usuários. Foi importante esta atividade ter sido 
realizada com as profissionais para entender o problema de uma forma mais técnica, vendo o quesito emocional por uma visão externa, que não a do próprio usuário. Nesta atividade, o papel de mediador do designer apresentou-se bem importante, visto o número de pessoas e a necessidade de se manter ao entorno do objetivo da conversa.

No final desta etapa, foi possível definir o escopo do projeto e contrabriefing levando como prioridade a mobilidade acessível em vias públicas. A proposta foi definida como a criação de um sistema de informações urbanas através do auxílio de pistas multissensoriais.

\subsection{Etapa de Criação e Ideação:}

Na etapa de Criação ou fase de Ideação, foi possível dar sentido à aquilo que foi ouvido nas etapas anteriores, gerando ideias para solucionar o briefing/contrabriefing. A etapa foi representada inicialmente por uma síntese do conhecimento adquirido nas pesquisas e entrevistas, onde foram identificadas oportunidades e estas foram validadas e desenvolvidas junto ao usuário, resultando em concepts. Partiu-se então para a geração de ideias e refinamento. Nesta etapa, esteve mais presente o usuário, que auxiliou a validar todas as informações e participou de processos de cocriação, dando suas próprias contribuições no projeto.

Primeiramente, foram desenvolvidos Mapas de Jornada do usuário, os quais auxiliam a visualizar o processo da experiência do usuário em sua jornada (do início ao fim) e onde o produto projetado pode ser encaixado (Milton \& Rodgers, 2013). As jornadas foram baseados nas entrevistas anteriores, e representavam objetivos que desejavam ser alcançados. Também foram desenvolvidos Cenários, ferramenta que projeta previsões imaginárias de um futuro hipotético através de conhecimentos do cenário atual (Reyes, 2016). Os cenários desenvolvidos trabalhavam o eixo "digital e analógico" e focavam na materialização do sistema de auxílio de informação.

Estas duas foram de fato, as primeiras ferramentas que precisaram ser totalmente adaptadas para os usuários entrevistados, visto que se baseiam em instrumentos visuais. As ferramentas foram validadas em uma sessão de cocriação com cinco convidados cegos da ACELB (Associação de Cegos Louis Braille) que tinha como objetivo receber feedbacks do público, ao possibilitar um momento de gerar ideias em conjunto. Nesta sessão, foram descritas as ferramentas anteriores e seus resultados através da fala narrativa, onde são descritos detalhes, sentimentos e comportamentos.

Os Mapas de Jornada, geralmente representados através de infográficos, foram apresentados através de narração para os participantes, e uma atividade como Role Play foi encenada. Nela projetou-se papéis de cada um dos mapas nos participantes e encenadas as situações hipotéticas através da narração, assim, os insights trazidos por eles foram mais verídicos à sua realidade. Já os cenários, geralmente representados através de desenhos e Moodboards, foram também narrados, agora, como pequenas situações fictícias. Foram descritos contextos, cenários, personagens, objetos, sentimentos e sensações.

A cocriação também foi um espaço onde os entrevistados através do diálogo, ajudaram a ilustrar possíveis soluções aos problemas cotidianos vividos por eles mesmos, levando em consideração o cenário por eles validado (cenário de equilíbrio entre analógico e digital). Para auxiliar na criação, foram levados materiais de desenho e escrita adaptados, como folhas de material e.v.a. e lápis de ponta grossa, que poderiam ser usados para desenho em relevo. 
Como apoio de captação de dados e informações, além da gravação em áudio, foi importante trabalhar montando mapas conceituais sobre o que estava sendo conversado. Os mapas são uma ferramenta gráfica de representação visual de hierarquia simplificada de informações complexas - palavras e ideias (Novak \& Cañas, 2006). Mesmo não sendo uma ferramenta adaptada, ela serviu para criar links entre os conteúdos conversados, que foram sendo perguntados, comentados e confirmados com os próprios participantes ao longo da cocriação.

O resultado da sessão de cocriação foram os concepts de projeto organizados dentro de um sistema. Cada um representando uma resposta de projeto materializado em um artefato físico multissensorial que alertaria sobre obstáculos ou informaria sobre o ambiente ao redor, e unidos em um sistema.

Após uma validação com profissionais onde foram definidos os concepts a serem seguidos, precisava-se entender onde cada artefato do sistema deveria ser aplicado corretamente na cidade. Foi necessário, portanto, delimitar o espaço de atuação do sistema, e para isso, entender onde os obstáculos e os pontos de interesse ficavam localizados no Centro de Porto Alegre, local escolhido para a aplicação do sistema-produto devido a sua complexidade. Para esta delimitação, foram utilizadas duas abordagens de "empathy field trips": a primeira, uma observação por meio de caminhada no centro; a segunda, uma atividade de Guided Tour. Uma ferramenta de imersão na vida do usuário, materializada em momentos guiados pela pessoa que está sendo observada, o que auxilia na observação de hábitos e na sensibilização do contexto (Ideo, 2009).

No Guided Tour, foi solicitado acompanhar 3 cegos em trajetos na rua, Figura 1. Diferente da ferramenta tradicional onde o trajeto é guiado, e são feitos comentários e perguntas durante o percurso, aqui optou-se por não interferir na atividade. Dessa forma, sendo mais fácil identificar de longe os obstáculos que interferiam no trajeto no usuário, como por exemplo, os postes, fradinhos e orelhões; também necessidades durante a atividade e o comportamento do público externo ao redor com o deficiente visual, atitudes de apoio ou descaso. A atividade apenas foi comentada quando no destino final.

Figura 1 - Atividade de Guided Tour.
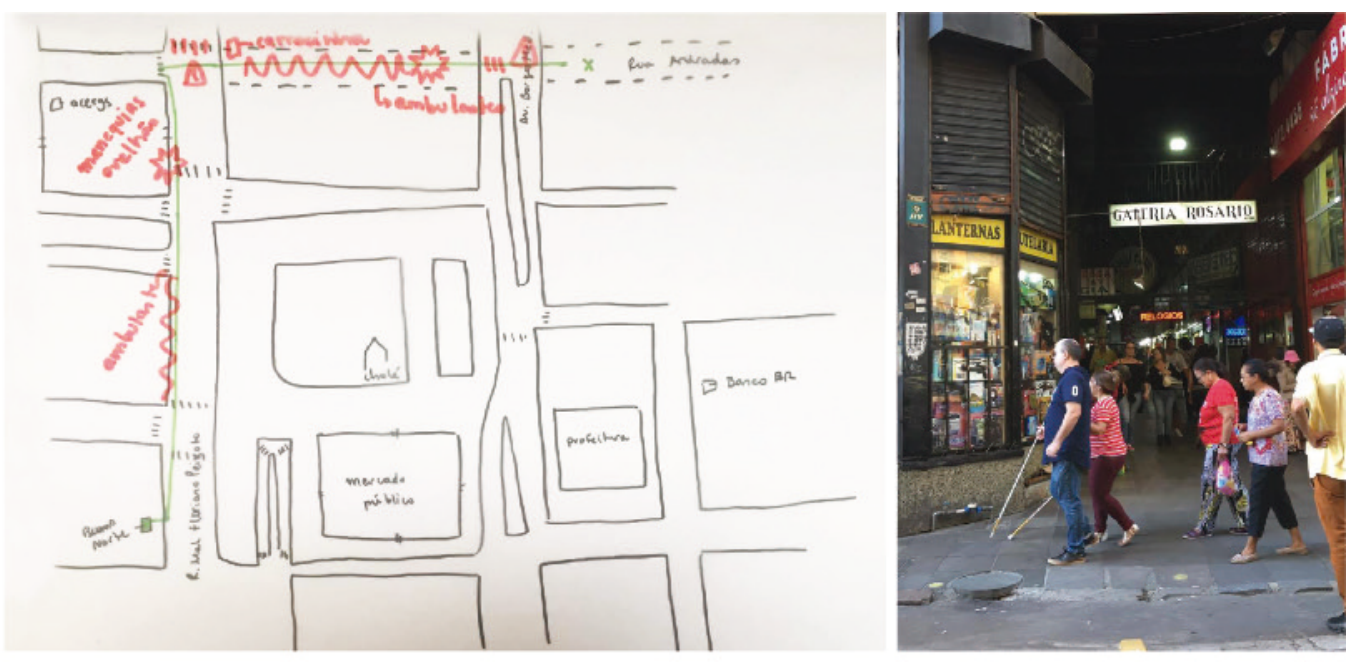

Fonte: autora (2017). 
Identificados os perímetros de atuação, o processo de imersão permitiu que se alcançasse uma espécie de hierarquia iminente dos obstáculos, sendo ela: obstáculos para alcançar (não perigosos), para desviar (leves), ou para evitar (perigosos); tendo como sub hierarquia: fixos ou temporários.

Foi utilizada por fim, a ferramenta de Card Sort, atividade que auxilia a identificar o que é importante para o usuário através de cartas com imagens ou palavras, ordenadas conforme suas prioridades (Ideo, 2009). Tinha-se aqui como objetivo utilizar uma ferramenta visual traduzido para o braille para o uso individual, mas por falta de recursos para a tradução, as cartas foram impressas em papel tradicional e adaptadas para o diálogo. Na tentativa de adaptar minimamente a ferramenta visual, optou-se por trabalhar de forma dinâmica como um questionário "jogo de perguntas e respostas rápidas".

Foram realizadas três entrevistas com deficientes visuais: um cego adquirido, um deficiente visual de baixa visão adquirida e uma cega congênita. E 23 cartas com obstáculos coletados, Figura 2, foram impressas, contendo o nome do obstáculo e duas questões: (1) O usuário quer alcançar ou desviar; (2) O sinal deve ser sonoro, olfativo, tátil ou não deve ter. As cartas serviram como apoio tátil ao usuário, que ao manter o bolo em sua mão, ouviu atentamente as opções de cada carta e compreendeu a atividade como rápida e de respostas curtas, não-narrativas. Esta hierarquização auxiliou na definição dos dois artefatos, partes de um sistema-produto.

Figura 2 - Atividade de Card Sort.

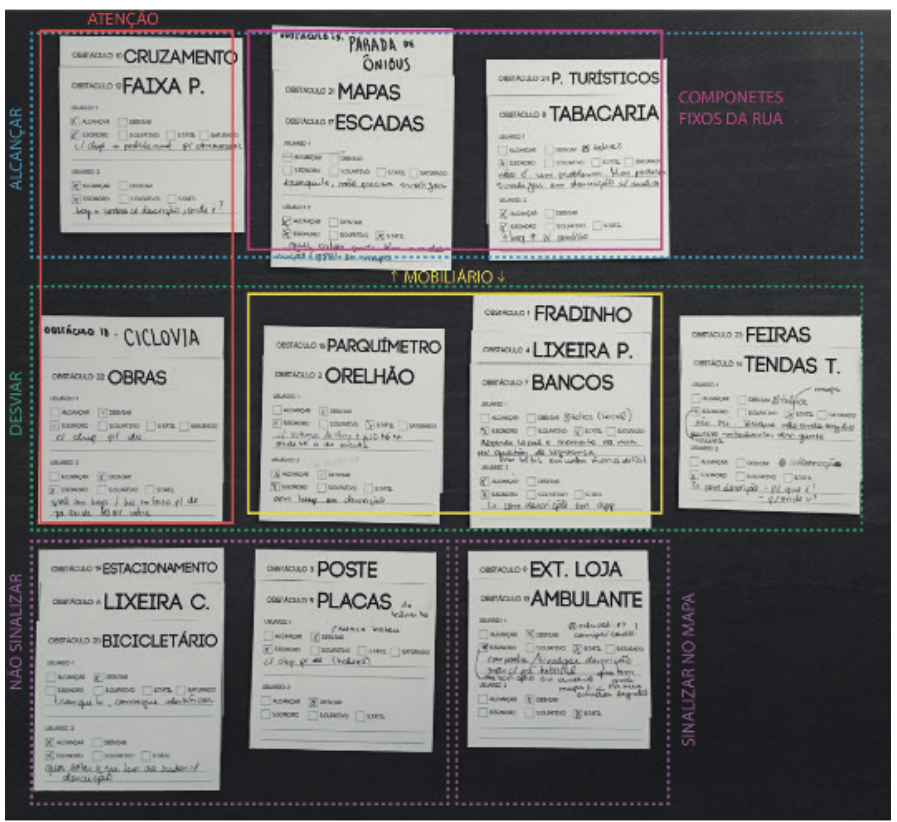

Fonte: autora (2017).

\subsection{Etapa de Entrega e Implementação:}

$\mathrm{Na}$ etapa final do projeto, após uma definição dos produtos a serem desenvolvidos e do funcionamento do serviço, foram feitos momentos de validação com dois dos deficientes visuais.

A primeira validação ocorreu após a geração de ideias, onde já haviam sido definidas questões funcionais e conceituais, mas ainda haviam dúvidas em relação à percepção, estética e 
capacidade de compreensão do produto. De forma a ilustrar a pesquisa de diretrizes estéticas e gráficas previamente realizada, foram criados mock-ups como apoio tátil, materiais de rápida prototipação, para que eles experimentassem e entendessem de forma mais tangível os produtos. Foram levados os modelos iniciais do artefato 1 - um mapa tátil feito de papel Paraná e corte a laser, com uma placa de informação em braille impressa em 3D (com variações de módulos e peças); e do artefato 2 - pulseiras feita de Biscuit, com botões e texturas. Testes na Figura 3. É importante ressaltar que a adaptação desta ferramenta foi no sentido de não levar um modelo funcional/formal, mas de ter percebido a necessidade de gerar variações diferentes de mockups, especialmente em relação à materiais, texturas, curvas, saliências e outros atributos estéticos, com objetivo de percepção sensorial.

Figura 3 - Validação dos mockups.

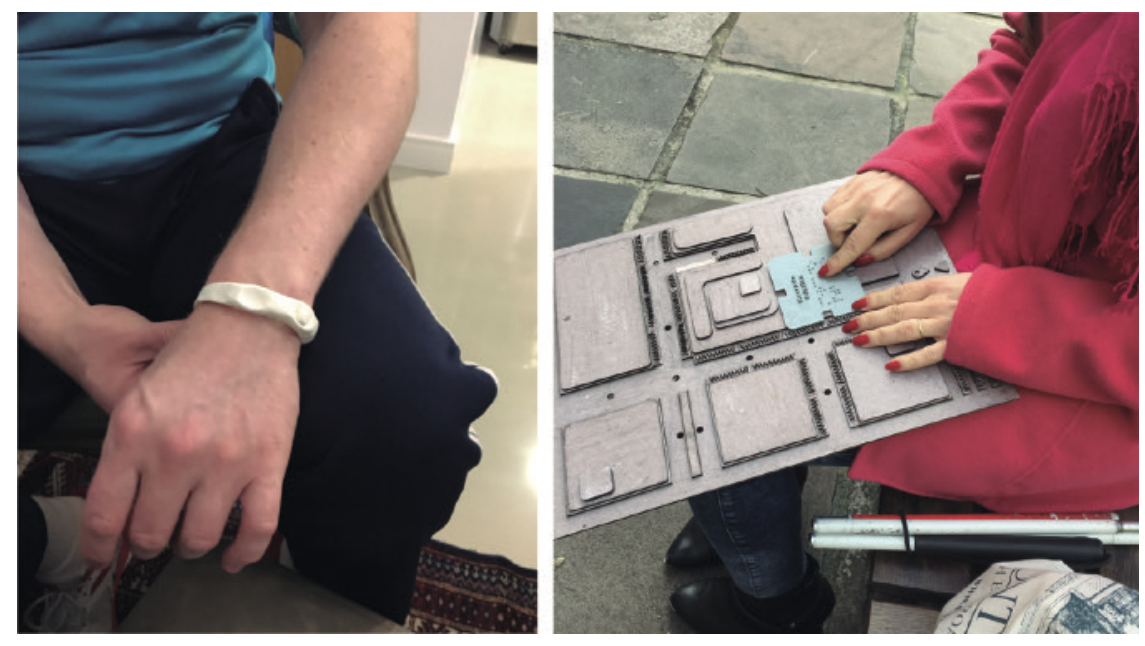

Fonte: autora (2017)

Após o desenvolvimento de todas as etapas do sistema-produto, pensou-se na possibilidade de simular uma situação de uso real dos produtos projetados. Assim, foi feita uma segunda validação, dessa vez com os protótipos finais. O objetivo da atividade era realizar um Life Prototyping, rodando o equipamento em rua sob condições reais durante um período de tempo pré determinado (Ideo, 2009). A atividade, porém, teve de ser adaptada ao contexto dos participantes da pesquisa, um perfil ainda inseguro de vivenciar a rua, sendo realizada na própria casa do usuário, mas então, com uma característica de Role Play, ao encenar possíveis situações hipotéticas na rua em ambiente protegido.

O protótipo final do mapa tátil foi feito com PS e peças texturizadas em impressão 3D e a pulseira foi feita também em impressão 3D e seu sistema de alertas em um dispositivo separado feito com Arduinos. Foram simuladas experiências de uso, colocando uma placa de Arduino no pulso do participante e a segunda em um poste. O resultado final do projeto foi prototipado graficamente dentro de um mapa de serviços com todas as etapas de implementação e uso dos artefatos, Figura 4. 
Figura 4 - Mapa de serviço.

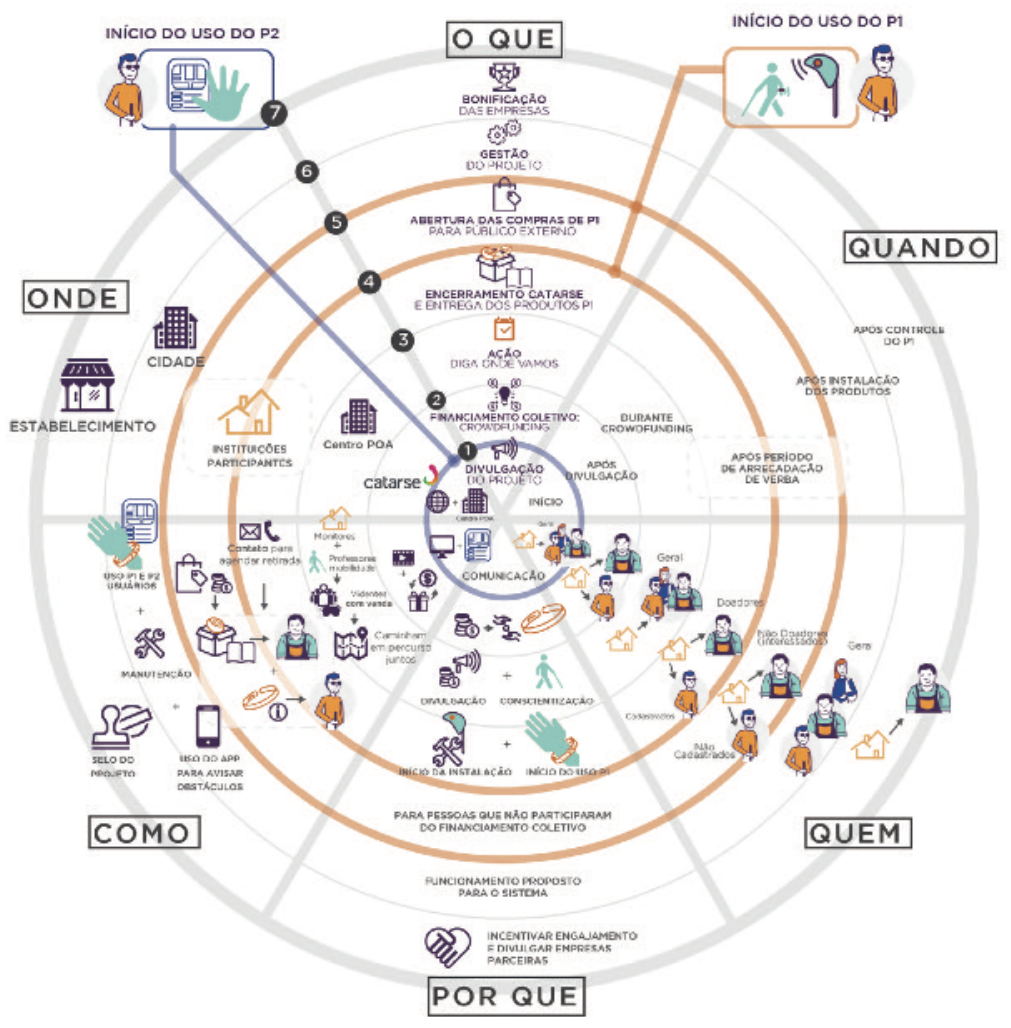

Fonte: autora (2017) .

\section{Discussão}

Em uma visão geral do processo, foi possível perceber que quando trabalhado com deficientes visuais, os sentidos utilizados podem ser divididos em dois momentos: primeiro, com um foco maior na audição e na fala, estimulando conversas que sensibilizam e transmitem conhecimento, onde o designer recebe muitos insumos. Já, o segundo momento, é estimulado mais o sentido do tato do usuário, através da criação e prototipação. O designer, depois de trabalhar sob os insumos, entrega ao usuário a materialização do discurso e da cocriação, de uma forma possível de sentir o resultado.

Quanto a este primeiro momento de conversa, é presente a sensibilização através da empatia. E, de acordo com Rosenberg (2006), para gerar empatia, é precisar treinar a capacidade de dar atenção e estar presente. Deixar que o usuário se expresse plenamente é essencial, porém, é percebido no ser humano uma forte tendência a aconselhar, encorajar, explicar a própria posição ou sentimento. Estes aspectos se confundem com o propósito da empatia, que requer uma concentração plena e sem vazamentos da mensagem da outra pessoa. Para que ela ocorra, é preciso dar tempo e espaço para a expressão, ceder certa posição de controle e transmitir interesse genuíno por seus sentimentos e necessidades. Manter a atenção, permite compreender não apenas a mensagem inicial que está sendo dita (a ponta de um inceberg) mas também, sentimentos não expressos relacionados às necessidades e desejos fundamentais. 
Foi importante, portanto, nos primeiros contatos, considerar duas características da metodologia participativa: construir um relacionamento de confiança com os usuários participantes, gerando um primeiro vínculo para uma conexão mais emocional e empática. "A empatia é a compreensão respeitosa do que os outros estão vivendo" (Rosenberg, 2006, p. 133). E, em relação a um início de imersão em contexto, ganhar conhecimento do público e seu ambiente, através da atenção e da concessão do controle à sua fala (Shea, 2012). Nesse sentido, o designer deve trabalhar como facilitador das conversas, incitando perguntas e recebendo seus insights. Nos diálogos durante as entrevistas, foi desenvolvido o uso de perguntas empáticas (o que sente e precisa) ao invés de perguntas analíticas (o que, quando, onde, como), o que estimula mais a abertura emocional do usuário com o designer.

No encaminhar do processo, onde já havia sido construída certa relação de confiança, foi incentivada a troca de conhecimentos durante uma sessão de cocriação. Nela, foram gerados insights de possíveis soluções para as barreiras da mobilidade urbana, também através da conversa. Aqui, se mostrou necessário mediá-la, questionando em relação às ideias, mas deixando que o grupo se expressasse livremente. Na fala dos usuários, percebeu-se que algumas necessidades ditas por eles não estavam sendo identificadas no projeto até então. Por exemplo, que a solução não deveria ser apenas destinada à auxiliar o deficiente visual, mas também informar o público vidente. Assim como outras necessidades que haviam sido identificadas previamente identificadas, mas não eram de fato priorizadas pelo público como o fato de que, não fazia sentido para eles um objeto muito tecnológico como solução, visto que o grande público não havia recursos para adquirí-lo.

Por trabalhar apenas com o diálogo nas sessões e entrevistas, percebeu-se que os insights dos participantes chegavam muitas vezes em formatos mais narrativos e criativos, como histórias. $\mathrm{O}$ que difere, de certa forma, de atividades visuais feitas em formato brainstorming com post-its, que oferecem informações de outra natureza. Um exemplo das histórias contadas por eles, foi de um dos participantes descrevendo uma solução possível ao problema durante a cocriação: "Para alertar os obstáculos, poderiam ser feitas cortinas de sinos distribuídas pelo local, e que alertariam os obstáculos quando ao vento".

Por fim, através dos testes e dos mockups, especificamente, foi possível materializar os produtos e gerar feedbacks positivos e negativos. O mapa tátil, por exemplo, permitiu testar as legendas, os espaços e os relevos com os usuários, onde alguns destes relevos apresentavam-se incompreensíveis pelos usuários, e isso mostrou uma necessidade de ajuste do item. Os testes com as legendas também fizeram perceber a necessidade de um trabalho mais apurado de prototipação, visto a diferença de percepção de um cego congênito para um cego adquirido.

Os participantes mostraram-se muito satisfeitos em receber os protótipos para o teste, pois eles auxiliaram a materializar tudo o que antes estava apenas no âmbito do diálogo durante as entrevistas, fazendo com que fossem estimulados outros sentidos durante este processo participativo.

\section{Considerações Finais}

Ao longo do desenvolvimento desta pesquisa, foi possível identificar uma evolução na 
pesquisa em Design Estratégico aliada à metodologia do Design Participativo. Se tratando de um tema envolvendo uma questão social, definido como um wicked problem, foi imprescindível a participação do público deficiente visual em momentos de pesquisa e validação, o que possibilitou compreender melhor seus problemas, necessidades e contexto, e ainda, estabelecer uma relação empática. O projeto com foco em uma ação co-participativa utilizando ferramentas adaptadas aos usuários, permitiu arrecadar uma variedade de insights, informações e considerações, e também passar por um processo de maior sensibilização ao tema. Envolvendo o público em decisões de projeto, foi possível uma maior interação e criação de um vínculo de confiança e respeito, reduzindo possíveis riscos de decisões equivocadas baseadas em conceitos pré-estabelecidos, reforçando o que foi trazido no capítulo 2.2 sobre a precisão do resultado ao criar consultando informações direto com o público/fonte.

A pesquisa também demonstrou que não existe uma forma única e correta de utilizar as ferramentas de design. Ao contrário, ficou claro que elas são passíveis de ajustes e adaptações dependendo de quem fará uso delas e da situação do uso, sem perder, porém, seu propósito ou objetivo. Uma vez entendidas as circunstâncias dos participantes dos processos, foi possível integrar diferentes atores (usuários e profissionais), cada um com suas respectivas visões e contextos, que tiveram a oportunidade de contribuir de forma ativa e autêntica.

Durante a pesquisa, também foram levantados fatores que influenciam no processo participativo e desafiam o papel do designer, como: o tempo necessário para uma colheita de informações usando a metodologia; a necessidade de um maior desprendimento do controle total da gerência do projeto, permitindo intervenções e opiniões externas; a construção do vínculo de confiança, através de uma frequência na presença em espaços de trabalho e vivência do usuário e a criação de canais de comunicação, que possibilitaram uma imersão no contexto apresentado; e uma mudança do papel do designer de desenvolver para, também, articulador e mediador.

Por fim, pretendeu-se com esta pesquisa praticar a responsabilidade social do designer através de um projeto que muniu-se da construção coletiva, do empoderamento da metodologia do design pelos participantes, e da adaptação de processos para meios não visuais, de forma a contribuir positivamente para a qualidade de vida das pessoas portadoras de deficiência visual, auxiliando no primeiro nível de autonomia da vida cotidiana, a mobilidade.

\section{Referências}

BATTARBEE, K.; SURI, J. F.; HOWARD, S. G. Empathy on the edge. Scaling and sustaining a Humancentered approach in the envolving practice of design. IDEO, 2014.

BINS ELY, V. H. M. Orientar-se no espaço: Condição indispensável para a Acessibilidade. In: Seminário Acessibilidade no Cotidiano, 2004. Florianópolis, 2004.

DEL GAUDIO, C. D.; OlIVEIRA, A. J.; FRANZATO, C. O tempo do Design Participativo. Anais do 110 Congresso Brasileiro de Pesquisa e Desenvolvimento em Design, Blucher Design Proceedings, São Paulo, v. 1, n. 4, p.957-969, 2014.

DISCHINGER, M. DESIGNING FOR ALL SENSES: Accessible spaces for visually impaired citizens. 270 f. Tese (Doutorado) - School Of Architecture, Chalmers University Of Technology, Sweden, 2000.

EUROPEAN DISABILITY FORUM. EDF Policy Paper: Development Cooperation and Disability. 
Brussels, 2016.

FALCATO, J. S.; BISPO, R. Design Inclusivo: Acessibilidade e Usabilidade em Produtos, Serviços e Ambientes. Lisboa: Centro Português de Design, 2006. 77 slides, color.

FRANZATO, Carlo. O design estratégico no diálogo entre cultura de projeto e cultura de empresa. Strategic Design Research Journal, [s.I.], v. 3, n. 3, p.89-96, 31 dez. 2010. UNISINOS - Universidade do Vale do Rio Dos Sinos.

GILL, M (Org). Deficiência Visual. Cadernos TV Escola, Ministério da Educação (MEC), Secretaria de Educação a Distância, Brasília, 2000.

IDEO. Human-Centered Design toolkit. 2009. Disponível em: <http:// www.hcdconnect.org/ toolkit/en/download>. Acesso em: 10 mar. 2014.

MANZINI, E. Service Research and Universities: towards a "service paradigm". INDACO-DIS, Politecnico di Milano, 2004.

MANZINI, E.; FRANZATO, C. Design: quanto todos fazem design: uma introdução ao design para inovação social. Ed. Unisinos, São Leopoldo, 2017.

MERONI, Anna. Strategic design: where are we now? Reflection around the foundations of a recent discipline. Strategic Design Research Journal, [s.I.], v. 1, n. 1, p.31-38, 1 dez. 2008. UNISINOS.

MILTON, A.; RODGERS, P. Research methods for Product Design. London, 2013.

NOVAK, J. D.; CAÑAS, A. J. The Theory Underlying Concept Maps and How to Construct Them. Florida Institute for Human and Machine Cognition, 2006. Tradução de Luis Fernando Cerri.

OLIVEIRA, L. M. B. Cartilha do Censo 2010: Pessoas com Deficiência. Brasília, 2012. 32 p.

PALLASMAA, J. 2005. The Eyes of the Skin: Architecture and the Senses. 2a ed., London, 80 p.

RITTEL, Horst.; MELVIN, Webber. Dilemmas in a General Theory of Planning. In: Policy Sciences, 1973. v. 4. p. 155-169.

ROSENBERG, M.; Comunicação não-violenta: técnicas para aprimorar relacionamentos pessoais e profissionais. Ágora, São Paulo, 2006.

SAMPAIO, L. R.; CAMINO, C. P. R.; ROAZZI, A. Revisão de Aspectos Conceituais, Teóricos e Metodológicos da Empatia. Psicologia, ciência e profissão, 2009.

SANDERS, E. B. N. Postdesign and Participatory Culture. Proceedings Useful and Critical: The Position of Research in Design. University of Art and Design, Helsinki, 1999.

SANDERS, E. B. N. From User-Centered to Participatory Design Approaches. In: Design and the Social Sciences, J.Frascara (Ed.), Taylor \& Francis Books Limited, 2002.

SANDERS, E. B. N, Brandt, E.; Binder, T. A Framework for Organizing the Tools and Techniques of Participatory Design. Proceedings Participatory Design Conference 2010, PDC. Association for Computing Machinery (ACM), Sydney, p. 195-198. 2010.

SCALETSKY, C.C.; BITTENCOURT, P.; COSTA, F, C; REYES, P. E. B. Design estratégico em ação. São Leopoldo: Editora Unisinos, 2016.

SHEA, A. Designing for Social Change: Strategies for Community-Based Graphic Design. New York, Princeton Architectural Press, 2012. 